\title{
A CONTRIBUIÇÃO DOS CONTOS DE FADAS NO PROCESSO DE ENSINO E APRENDIZAGEM DAS CRIANÇAS.
}

Ademir Henrique Manfré, Adriana Prado, Fernanda Simões Machado

Universidade do Oeste Paulista - UNOESTE, curso de Pedagogia, Presidente Prudente, SP. E-mail: fermachado06@gmail.com

\begin{abstract}
RESUMO
Este artigotrata do tema "contos de fadas no processo deensino e de aprendizagem das crianças", abordando de forma significativa a importância que os referidos exercem na dimensão pedagógica e em quais aspectos podemfavorecer o desenvolvimento da criança. Apresenta uma abordagem qualitativa quefavorece a reflexão, a análise e a interação acerca das teorias e hipóteses levantadas.O questionamento que motivou a escolha desse tema foi: como os contos de fadas podem contribuir para o desenvolvimento da criança?Metodologicamente falando, a pesquisa bibliográfica realizada em periódicos educacionais foi a que sustentou toda a elaboração deste trabalho, em que foram utilizadas concepções de importantesautores da literatura infantil. A partir da revisão literária, foi possível concluir que,embora a contação de histórias apresenta-se como um rico meio para o desenvolvimento das habilidades cognitivasda criança, os docentes geralmente não têmconsciência de seu valor como suporte no processo de ensino-aprendizagem escolar.
\end{abstract}

Palavras-chave: Contos infantis. Escola. Formação docente.

\section{THE CONTRIBUTION OF FAIRY TALES IN THE CHILDREN'S LEARNING PROCESS.}

\begin{abstract}
This work has as its theme the contribution of fairy tales in the process of learning of children, addressing in a significant way the importance that the fairy tales exert in the pedagogical dimension and in what aspects can favor the development of the child. It presents a qualitative approach that favors reflection, analysis and interaction about the theories and hypotheses raised.The question that motivated the choice of this theme was: How fairy tales can contribute to the development of the child. The bibliographical research was the one that supported the whole elaboration of this work, in which were used conceptions of important authors of children's literature. From the literary review, it was possible to perceive that, although storytelling presents itself as a rich medium for the development of children's abilities, teachers are generally unaware of their value as a support in the teaching-learning process.
\end{abstract}

Keywords: Children's stories. School. Teacher training. 


\section{APRESENTAÇÃO: SITUANDO O DEBATE}

O presente artigo tem como tema "A Contribuição dos Contos de Fadas no Processo de ensino e de aprendizagem das Crianças." Fundamenta-se a partir de um recorte de nossa pesquisa de Iniciação Científica cadastrada junto à CPDI/UNOESTE, recebendo o protocolo de cadastro de ${ }^{\circ}$ 4154. A pesquisa completa será apresentada em forma de relatório científico junto à CPDI em dezembro deste ano.

Este trabalho teve como propostageral refletir, dentro de uma dimensão pedagógica,sobre como os contos de fadas podem contribuir para o processo de ensino e de aprendizagem da criança no período escolar, uma vez que os referidos estão muito presentes na didática usada em sala de aula pelo docente.

De acordo com Bettelhein (1980), os contos de fadas são amplamente pertinentes à aprendizagem da criança, não só como uma forma de literatura, mas também como objeto integral e compreensível para elas, como um momento de distração e desenvolvimento de suas habilidades, levando-as a uma nova percepção do mundo imaginário na qual permitem a elas explorar sua criatividade e seus pensamentos.

Diante desse parâmetro, a definição mais profunda dos contos de fadas será sempre diferente para cada individuo, e distinto para o mesmo sujeito em váriosmomentos de sua vida.

Partimos do pressuposto de que o contato com os contos de fadas possibilita à criança o ensaio de vários papéis sociais, proporcionando a ela uma troca de experiências e uma maior inserção no grupo social (ALBERTI, 2006).

Diante do exposto, os contos de fadas ao serem tratados de forma significativa na escola, não só contribuirá para o processo de ensino e de aprendizagem da criança, como também ajudará ela a realizar uma análise crítica diante dos seus conflitos, possibilitando uma reflexão de forma significativa.

Assim, o nosso objetivo foi pensar, discutir e refletir, a partir de uma dimensão pedagógica, sobre a importância dos contos de fadas na formação da criança.

\section{METODOLOGIA: OS CAMINHOS TRILHADOS:}

A metodologia proposta para a presente investigação é de natureza qualitativa e de base bibliográfica. Os caminhos trilhados para a investigação proposta consistiu em um levantamento bibliográfico em teses e dissertações de mestrado, livros, além de artigos científicos cujo recorte temporal compreendeu os anos de 2005 a 2015.

Devido à limitação de laudas sugerida pelas normas científicas do evento para o envio de artigo completo, nos deteremos na apresentação de parte de nossa pesquisa científica.

\section{RESULTADOS: O QUE O MATERIAL CONSULTADO APONTA SOBRE A PROBLEMÁTICA AQUI EXPOSTA?}

A partir do levantamento bibliográfico realizado, constatamos que os contos de fadas estãopresentes na prática pedagógica dos docentes no interior das salas de aula. Foi possível evidenciar que a contação de histórias é utilizada como ferramenta pedagógica desde a formação inicial. Entretanto, a revisão literária apontou que,embora a contação de histórias apresenta-se como um rico meio para o desenvolvimento das habilidades cognitivas da criança, os docentes geralmente não têm consciência de seu valor como suporte no processo de ensino-aprendizagem escolar. Assim, ressaltamos a importância de se investir na formação docente para o trabalho significativo com a literatura de contos de fadas na escola básica.

Desse modo, é de extrema importância que o docente estude a simbologia e o contexto histórico do conto que vai trabalhar em sua prática pedagógica para que assim seja de grande significância para a aprendizagem da criança. 
Depois de ouvirem um conto de fadas, as crianças descobrem o protagonismo de cada personagem, compreendem o mundo das histórias fantásticas, da fantasia e da imaginação, e muitas delas começam a se identificar com alguns personagens.

Bettelhein (1980) anota que a criança, através da narrativa, pode identificar-se com um dos seus protagonistas não só recebendo influências, uma vez que é informado a ela que através do seu envolvimento e experiência com o conto poderá se sair vitoriosa de alguma situação ou vivência, mesmo havendo um oponente muito mais forte.

Portanto, podemos dizer que os contos de fadas ajudam a direcionar as crianças para uma descoberta de sua identidade e as auxiliam a compreender os conflitos de sua própria vivência.

Silva (2013) destaca a importância da utilização dos contos de fadas na educação infantil, pois é por meio dessa prática que vai estimulando a criatividade, a imaginação contribuindo para formação da subjetividade da criança. Ou seja, a criança vai se encontrando com cada história contada, relacionando características da história parecidas com as reais da sua vida.

Segundo o documento RCNEI (BRASIL, 1998, p. 163): "as vivências sociais, as histórias, os modos de vida, os lugares e o mundo natural são para as crianças parte de um todo integrado". Dito de outro modo, através das histórias, o contador pode despertar a imaginação dos ouvintes, transportando-os ao mundo da fantasia que está sendo criado ao seu redor.

O fato de a criança gostar de ouvir histórias é muito importante, uma vez que ela constrói dentro de si muitas ideias através de descobertas, de outros lugares, outras épocas, outros modos de agir, além de ter a curiosidade respondida podendo esclarecer melhor suas próprias dificuldades ou encontrar um caminho para a resolução delas.

A partir da revisão literária, apostamos na formação docente como fator diferenciador no processo de ensino-aprendizagem escolar com a utilização dos contos de fadas como ferramenta pedagógica.

\section{DISCUSSÃO}

Bettelheim (1980) anotao quanto é importante para a formação de qualquer criança ouvir histórias. Escutá-las é o início da aprendizagem para ser um bom leitor, tendo um caminho absolutamente infinito de descobertas e de compreensão do mundo. É poder sorrir, gargalhar com situações vividas pelos personagens e com asexperiências estabelecidas com os contos e com aquilo que os referidos representam para as crianças. A criançase torna participante desse momento de humor, de brincadeira e aprendizado através da leitura dos contos de fadas.

Ressurreição (2005) argumenta que os contos de fadas contribuem para o processo de ensino e de aprendizagem da criança na sua fase de formação educacional. Daí se explica suas aventuras terem como motivo central o encontro, a imaginação, a recriação, a união do cavaleiro com a amada (princesa ou plebeia) após vencer grandes obstáculos proporcionados pela maldade de alguém. Mas, no que se refere ao processo de ensino e aprendizagem, a ênfase está em analisar a importância do conto de fadas no trabalho pedagógico feito a partir da leitura deles.

Kupstas (1993) indica que na educação escolar, a literatura tem um espaço marcante para o trabalho pedagógico, e que é de grande valia para a criança ter contato com a literatura em seu processo de ensino e de aprendizagem, uma vez que estabelecendo um contato literário agregaráelementos significativos paraa sua formação. Os contos de fadas se fazem importantes dentro da literatura infantil com suas histórias.

Alguns autores como Irmãos Grimm, La Fontaine, Andersen entre outros mostram que através dos contos de fadas as histórias trazem grande benefício para formação da criança, sendo ela educacional ou subjetiva.

Machado, (1994, p.43) explica que:

No espaço sobrenatural não existe tempo real, tudo acontece de repente e justamente, com total arbítrio do acaso. Os personagens existem, mas não foram criados por leis humanas. São, antes, fenômenos naturais. Por isso são seres encantados. 
A educação precisa direcionar seus docentes para que eles saibam expressar a leitura dos contos de fadas de uma forma significativa para não correr o risco de privar seus alunos de vivenciar os benefícios que podem trazer depois de uma leitura bem feita e uma interpretação correta das histórias através de seus personagens.

Segundo Ferreira (1975, p. 918), “imaginar é construir ou conceber na imaginação; fantasiar, idear, inventar; é o ilusório; o fantástico. Imaginação: é a faculdade que tem o espírito de representar imagens. Imaginário: é o que só existe na imaginação".

\section{CONCLUSÃO}

Este trabalho, a partir de uma investigação bibliográfica, possibilitou refletir sobre a importância dos contos de fadas no processo de ensino e de aprendizagem das crianças, focando a possibilidade dos contos no desenvolvimento da imaginação e criatividade delas. Conclui-se que o contato com os contos de fadas possibilita à criança o ensaio de vários papéis sociais, proporcionando uma troca de experiências e uma maior inserção no grupo social.

A leitura realizada a partir do levantamento bibliográfico revelou que, através dos contos, as crianças se descobrem, desenvolvem habilidades como a comunicação, socialização, bem como a formação de sua personalidade, pois as crianças se identificam com os personagens das histórias e se encantam com esse mundo imaginário. É de extrema importância que o docente saiba trabalhar essa temática em sala de aula, de maneira lúdica, contribuindo significativamente para o desenvolvimento dos escolares.

Através desse trabalho, foi possível notar o quanto esse tema ainda é pouco ressaltado no âmbito da preparação dos docentes. Muitos não conhecem a riqueza desses contos, tampouco a melhor forma de trabalhar dentro de sala de aula, ignorando muitas vezes a prática de leitura na escola. É possível notar que um conto terá um significado diferente para cada criança de acordo com a sua realidade.

Para aproximar o aluno da leitura, faz-se necessário que o professor atribua à literatura uma finalidade prazerosa e não apenas cumprir obrigações curriculares na escola ou no trabalho, pois só assim será possível formar leitores críticos e interessados.

A iniciação da narrativa dos contos na Educação escolar pela criança é necessária e importante. Nesse contexto, percebemos o quanto é fundamental o papel do professor, pois será de sua responsabilidade proporcionar aos estudantes espaços adequados de leitura, transformando esses espaços em situações prazerosas de aprendizagem. Os contos de fadas são primordiais para a experiência da leitura, da formação da criança, já que esses são histórias que cativam os leitores de todas as idades.

O papel do professor é primordial nessa conjuntura. A escolha que se faz de uma história é um primeiro passo apenas. Os contos de fadas devem ser transformados em personalidades do contador, em realidade contada, sentida por tons, gestos e percepções diferentes.

Como nos aponta Bettelheim (1980), enquanto diverte a criança, o conto de fadas esclarece sobre quem é ela em um contexto muito mais amplo e favorece o desenvolvimento de sua identidade. Ele "oferece significado em tantos níveis diferentes e enriquece a existência da criança de tantos modos que nenhum livro pode fazer justiça à multidão e diversidade de contribuições que esses contos dão à vida da criança" (BETTELHEIM, 1980, p. 20).

Diante da amplitude que caracteriza a temática, nosso intuito aqui foi trazer um recorte do levantamento bibliográfico proposto no que se refere ao papel do professor na estimulação da imaginação na infância e, possivelmente, pensar a formação docente como um elemento fundamental para esse processo. 


\section{REFERÊNCIAS}

ALBERTI, P. B. Contos de fadas tradicionais e renovados: uma perspectiva analítica. 130 p. 2006.

Dissertação apresentada ao programa de Pós Graduação - Caxias do Sul, 2006.

BETTELHEIM, Bruno. A Psicanálise dos Contos de Fadas. Rio de Janeiro, Paz eTerra, 1980.

BRASIL. Ministério da Educação e do Desporto. Referencial Curricular Nacionalpara a Educação Infantil. Brasília, DF, 1998.

FERREIRA, Buarque Aurélio. Novo dicionário da língua portuguesa. Rio de Janeiro:Nova Fronteira, 1975.

KUPSTAS Márcia. et ali. Sete faces do conto de fadas. São Paulo. Moderna,1993.

MACHADO, Irene A. Literatura e redação. São Paulo: Scipione, 1994.

RESSUREIÇÃO, Juliana Boeira. A importância dos contos de fadas no desenvolvimento da imaginação. 2005.Disponível em: <http://www.Artigo.com/educação/>. Acesso em: 30 abr. 2014.

SILVA, Ana Maria. A importância da leitura dos contos de fada na educação infantil, 2013. Disponível em: <http://caosfilosófico.blogspot.com.br/artigo/>. Acesso em: 10 abr. 2014. 